Original article

\title{
Association of HLA -A1 and HLA -B8 Antigens with Natural Rubella Infection in Bangladeshi Females
}

\author{
Afzalunnessa, Shahina Tabassum, Saif Ullah Munshi, Md. Nazrul Islam \\ Department of Virology, Bangabandhu Sheikh Mujib Medical University, Shahbag, Dhaka
}

\begin{abstract}
HLA typing was carried out for HLA -A1 and HLA -B8 antigens among 40 Rubella specific immunoglobulin G (RSIgG) positive and 10 RSIgG negative subjects by employing microlympohocytotoxicity technique in viable $(>85 \%)$ lymphocytes separated from fresh blood. Among these, HLA-A1 antigen was detected in $20(50 \%)$ of RSIgG positive and 4 (40\%) of RSIgG negative subjects. The HLA-B8 antigen was detected in $1(2.5 \%)$ of RSIgG positive and in none of the RSIgG negative subjects. None of the subjects had both $\mathrm{A1}$ and $\mathrm{B8}$ antigens. Of the total subjects tested, 24 (48\%) were positive for A1 antigen but only $1(2.0 \%)$ was found positive for B8 antigen. In conclusion, HLA -A1 antigen was more frequently found in local population than $\mathrm{B8}$ antigen. However, in this study, a positive correlation of $\mathrm{A} 1$ and $\mathrm{B8}$ antigens with natural rubella infection could not be established.
\end{abstract}

Key words: HLA, Rubella specific immunoglobulin

\section{Introduction}

Since the discovery of the antigens of major histocompatibility system (HLA), there has been an intensive search for correlations between these genetic markers and specific disease states. ${ }^{1,2,3}$ A considerable number of diseases, including rubella, have been reported to be associated with particular HLA antigens. ${ }^{4}$ In their study, Honeyman and Menser showed a positive correlation between worldwide rubella epidemiology and the frequency of HLA-A1 and HLA-B8 antigens. ${ }^{5}$ The investigators suggested that individuals with HLA-A1 and HLA-B8 have an increased susceptibility to infection and a high potential for spreading rubella virus. The mean gene frequency of HLA-A1 and HLA-B8 in a population may therefore be related to the efficiency of transmission of rubella in the community. It may also be the reason for the comparatively lower proportion of women immune to rubella in islands such as Hawaii, Jamaica, Trinidad and rural Japan, where the mean gene frequency of HLA-A1 and HLA-B8 is low. 6,7,8.

Correspondence:

Dr. Afzalunnessa, Assistant Professor, Department of Virology BSMMU, Shabagh, Dhaka.
The endemicity of rubella has already been established in Bangladesh. ${ }^{9}$ The prevalence of rubella antibody was found to be $80 \%$ between $16-20$ years of age and peaked to $90.2 \%$ with increasing age. 9,10 Although rubella is generally a mild illness, however, when contracted by pregnant women, especially those in their first 16 weeks of pregnancy, it frequently causes serious complications including miscarriage, abortion, still birth and congenital rubella syndrome (CRS). ${ }^{11,12}$ This higher prevalence of rubella antibodies, acquired by natural rubella infections among females of child bearing age, may cause a significant number of congenital rubella infection (CRI). Moreover, their genetic background may also influence this high prevalence of natural rubella infection as well as CRI. In this context, the present study was designed to detect an association of natural rubella infection with HLA -A1 or HLA-B8 antigens.

\section{Methods}

This study was carried out among 50 healthy, female hospital personnel, who were exposed to similar risks of natural rubella infection and had no history of rubella vaccination. The subjects were selected from doctors and nurses of BSMMU, between 25-35 years of age. The laboratory works were done at the Department of Virology, BSMMU, during 
the period of January, 2005 to June, 2005. Samples were tested for the presence of RSIgG by chemiluminescent Enzyme Immunoassay performed in Immulite Automated Immunoassay system (DPC Immulite, Germany) with commercially available kits (Inmulite Rubella Quantitative IgG, DPC) according to the manufacturer's instructions.

Typing of HLA antigens:

HLA typing was done among 50 individuals (40 RSIgG positive and 10 RSIgG negative) by the National Institute of Health (NIH) microlymphoacytotoxicity methods. ${ }^{13}$

Principle of microlymphocytotoxicity test:

Isolated target lymphocytes are incubated with human or monoclonal serum containing known antibodies directed against HLA antigens found on the lymphocyte surface. The cell-serum mixture is combined with rabbit serum known to have complement reactivity against the human antigen antibody complex. The presence of an antigen-antibody complex effectivity "fix" complements which, in turn, result in a breakdown of the cell membrane. Thus, target cells against which an antibody has been directed and had fixed the complement will have their cell membranes compromised. Conversely, target cells that do not express antigens against which the antibodies are directed, will not fix complement and the cell membranes remain intact. Uptake of a fluorescent label or vital dye indicates compromise of the cell membrane. The percentage of dead cells is determined by an appropriate method and the data is scored according to guidelines.

Procedure:

$5 \mathrm{ml}$ of fresh blood was collected in a heparin-containing test tube and the lymphocytes were separated immediately by Ficoll-Hypaque (Sigma Diagnostics, USA) density gradient centrifugation technique, as described by Boyum (1968) and subsequently modified by Jondal. ${ }^{14}$ An amount of $1 \mu l$ of lymphocyte suspension was added to each well of Terasaki tray containing $1 \mu \mathrm{l}$ HLA anti-sera and incubated for 30 minutes. Then, $5 \mu 1$ of rabbit complement was added to each well and allowed to incubate for 1 hour. After the incubation, $3 \mu \mathrm{l}$ of $5 \%$ eosin dye was added and again incubated for 3 minutes. The reaction was fixed by adding $5 \mu 1$ buffered formaldehyde to each well and the tray was then covered and stored at $8^{\circ} \mathrm{C}$. Reading was taken after 24 hours under an inverted microscope. Interpretation of result was carried out according to manufacturer's instructions. Evaluation of HLA antigens were graded as following: negative (0-10\% lysed cells), doubtful (11-20\% lysed cells), weakly positive (21$50 \%$ lysed cells), positive (51-80\% lysed cells) and strongly positive (81-100\% lysed cells).

Statistical analysis:

Data obtained from the study were entered into SPSS version 12.0 for windows and analyzed. Comparisons between groups were done by Chi-squire test. Probability less than 0.05 were considered as significant

\section{Results}

Of the 50 study subjects, $40(80 \%)$ were found to be positive and $10(20 \%)$ were negative for RSIgG. Both RSIgG positive and negative subjects were enrolled for HLA-A1 and HLAB8 antigen detection. Among RSIgG-positive subjects, 20 $(50 \%)$ were positive for HLA-A 1 , only 1 (2.5\%) was positive for HLA-B8 and rest 19 (47.5\%) were negative for both the antigens. Among 10 rubella antibody negative subjects, 4 (40\%) were positive for HLA-A1 and none was found to be positive for B8 antigen. Both HLA-A1 and HLA-B8 antigens together were not found in any tested sample. The frequency of HLA antigens among both RSIgG positive and negative subjects showed that HLA-A1 antigen is more in RSIgG positive subjects, but this difference is not statistically significant. (Table I)

Table I: Frequency of Human Leukocyte Antigen (HLA-A1 and HLA-B8) among Rubella antibody positive and antibody negative study subjects

\begin{tabular}{llccc}
\hline HLA -A1 antigen & HLA-B8 antigen & \multicolumn{3}{c}{ Rubella specific IgG } \\
& & Positive $(\mathrm{n}=40)$ & Negative $(\mathrm{n}=10)$ & Total \\
\hline A1 positive & B8 Negative & $20(50 \%)$ & $4(40 \%)$ & 24 \\
A1 Positive & B8 positive & 00 & 00 & 00 \\
A1 negative & B8 Positive & $1(2.5 \%)$ & 00 & 01 \\
A1 negative & B8 negative & $19(47.5 \%)$ & $6(60 \%)$ & 25 \\
\hline
\end{tabular}

Chi-squire test was done. $\mathrm{P}=<0.05$, result not significant. 


\section{Discussion}

Rubella virus infection is of major public health importance as the disease produces particular threat to the developing fetus if contracted during early pregnancy. ${ }^{15,16}$ In utero infection of the fetus may result in congenital deformities like cataract, congenital heart disease, deafness and mental retardation. ${ }^{17,18}$ To prevent such hazards, it is therefore essential for young girls to develop immunity against rubella by the time they reach childbearing age. In the present study it was found that $81.7 \%$ of females between $25-35$ years, acquired rubella antibody by natural rubella infection. Available data from many developing countries of South-east Asia and Africa show similar pattern of antibody distribution. ${ }^{8,19,20}$ Most of the industrialized countries also had a similar pattern of rubella antibody prevalence before the introduction of rubella vaccination program. ${ }^{21}$

A positive correlation with worldwide rubella infections and Human Leukocyte Antigens (HLA) has been observed especially with the frequencies of HLA-A1 and B8.5 In areas where the prevalence of rubella antibody is low, the frequencies of HLA-A1 and B8 are also low. It is possible that these populations are genetically less susceptible because of lower frequency of HLA-A1 and B8 antigens. In our study, it was found that $50 \%$ of RSIgG positive subjects had A1 antigen and $2.5 \%$ had B8 antigen. Among RS IgG negative individual, $40 \%$ had HLA-A1 antigen but none had B8 antigen. The reason for this may be that the number of RSIgG negative subjects in our study was relatively small. The frequency of HLA-A1 antigen in local population has been found to be $33 \%$ and B8 was $0.7 \%$ (personal communication). As such, in a population with $33 \%$ HLA-A1 and $0.7 \%$ HLA -B8 antigens, $50 \%$ of RSIgG positive subjects were HLA-A1 positive and $2.5 \%$ were HLA-B 8 positive. This indicates that HLA-A1 antigen frequency was more in our study population as well as in RSIgG-positive subjects.

The overall finding of this study suggests that Bangladeshi females may be genetically more susceptible to natural rubella infection. However, further extensive studies with larger number of subjects should be carried out with a view to delineate the association of HLA antigen with rubella virus infection in Bangladesh.

\section{Reference}

1. Oh JH, Maclean LD. Disease associated with specific HLA antigens. Can Med Assoc J 1976; 112: 1315-1318.

2. Dausset J, Degos L, Hors J. The association of the HLA antigens with disease. Clin Immunol Immunopathol 1974; 3: 127-149.

3. McDevitt HO, Bodmer WF. HLA immune-response genes and disease. Lancet 1974; 1: 1269-1275.

4. Dousset J, Svejgard, A. HLA and disease predisposition to disease and clinical implications. Paris: Editions Inserm; 1976.

5. Honeyman MC, Menser MA. Ethnicity is a significant factor in the epidemiology of rubella and Hodgkin'.s disease. Nature 1974; 251: 441-442.

6. Rawls WE, Melnick JL, Bradstreet, et al. WHO collaborative study on the sero-epidemiology of rubella. Bull WHO 1967; 37 : $79-88$.

7. Halstead SB, Diwan AR, Oda AI. Subsecptibility to rubella among adolescents and adults in Hawaii. J Am Med Assoc 1969; 210: 1881-1883.

8. Dowdle WR, Ferreira W, DeSallesgomes LF, et al. WHO collaborative study on the sero-epidemiology of rubella in Caribbean and Middle and South American population in 1968. Bull WHO 1970; 42: 419-422.

9. Ashrafunnessa, Khatun S, Islam MN, Chowdhury S. Seroprevalence of rubella antibodies among antenatal population attending a tertiary level hospital in Dhaka city. Bangladesh Med Res Coun Bull 2000; 26 (3): 75-81.

10. Nahar N, Islam MN. Prevalence of rubella HI antibody in children and women in Dhaka. Bangladesh Med J 1987; 6: 1-5.

11. Centers for Disease Control. Rubella prevention recommendations of the advisory committee for immunization practices (ACIP). Mortal Morbid Wkly Rep 1990; 39 (RR-15): $1-18$.

12. Freiz BJ, South MA, Sever JL. Maternal rubella and the congenital rubella syndrome. Clin Perinatol 1988; 15: 247-257.

13. Ray JG, Hare DB, Kayhoe DE. NIH lymphocytotoxicity technique. In: Manual of tissue typing technique. Maryland: National Institute of Health; 1976: pp. 20-22.

14. Jondal M, Holm Y, Wigzell H. Surface markers on human T and B-lymphocytes and a large proportion of lymphocytes forming non-immune rosettes with sheep red blood cells. J Exp Med 1972; 136: 207-214.

15. Munro ND, Shepperd S, Smithells RW, Holzel H. Temporal relations between maternal rubella and congenital defects. 
Association of HLA-A1 and -B8 Antigens with Natural Rubella Infection

Lancet 1987; 2: 201-203.

16. Miller E, Cradock-Watson JE, Pollock TM. Consequence of confirmed maternal rubella at successive stages of pregnancy. Lancet 1982; 2: 781-784.

17. Wesselhoeft C. Medical progress - Rubella. N Engl J Med 1947; 236 (25): 943-950.

18. Ingalls TH, Babbott FL, Hampson KW, Gordon JE. Rubella, Its epidemiology and teratology. Am J Med Sci 1960; 239: 363-383.

19. Pal SR, Chitkara NL, Broor S, Murthy JG. Serological
Afzalunnessa et al

investigation of rubella virus infection in and around Chandigarh - a preliminary communication. Indian J Med Res 1974; 62: $240-245$.

20. Mathur A, Chaturvedi UC, Mehrotra RML. Serological study for the prevalence of rubella at Lucknow. Indian J Med Res 1974; 62: 307-312.

21. Rawls WE, Melnick JL, Bailey M, Ferris AA. WHO collaborative study on the seroepidemiology of rubella. Bull WHO 1967; 37: 79-88. 